\title{
Inoculação do feijão-caupi com rizobactérias promotoras de crescimento e desempenho na produção de biomassa
}

\author{
Cowpea inoculated with growth promoting rhizobacteria \\ and biomass production
}

Fabio Fernando de Araújo ${ }^{*}$, Ademir Sergio Ferreira de Araújo ${ }^{2}$, Marcio Reginaldo de Souza'

\author{
Faculdade de Ciências Agrárias, \\ Universidade do Oeste Paulista \\ (UNOESTE), Rod. Raposo Tavares, \\ Km 572, Limoeiro, CEP 19067-175, \\ Presidente Prudente, SP, Brasil \\ ${ }^{2}$ Centro de Ciências Agrárias, \\ Universidade Federal do Piauĩ (UFPI), \\ Teresina, PI, Brasil \\ *autor correspondente \\ 凶fabio@unoeste.br
}

RESUMO: O objetivo deste trabalho foi avaliar o desempenho de feijão-caupi (Vigna unguiculata) na produção de massa seca e fixação de nitrogênio $(\mathrm{N})$, utilizando-se da coinoculação das sementes com Bradyrhizobium sp. (SEMIA 6462) e Bacillus subtilis (prbs-1). O experimento foi conduzido em um Argissolo Vermelho Amarelo distroférrico, durante o período de abril a junho de 2009, em Presidente Prudente, SP. Foram estudados 4 tratamentos sob o delineamento experimental de blocos casualizados (T1- Feijão-caupi sem inoculação; T2- Feijão-caupi inoculado com Bradyrhizobium sp.; T3 Feijão-caupi inoculado com B. subtilis; T4- Feijão-caupi com Bradyrhizobium sp. e coinoculado com B. subtilis). A cultivar de feijão-caupi utilizada foi a BRS Guariba. Avaliou-se a nodulação, massa seca da parte aérea e acúmulo de $\mathrm{N}$ total em duas épocas (40 e 55 dias após a semeadura). A inoculação do feijão-caupi com a estirpe de Bradyrhizobium, recomendada comercialmente, aumentou a nodulação na planta. A simples inoculação do feijão-caupi com B. subtilis proporcionou o maior crescimento da planta, a fixação de $\mathrm{N}$ e não afetou a nodulação. Entretanto, na coinoculação não ocorreram ganhos nas variáveis avaliadas. No tratamento, em que se inoculou $B$. subtilis nas sementes de feijão-caupi, foram produzidos cinco megagramas de massa seca por hectare com acúmulo $209 \mathrm{~kg}$ de $\mathrm{N}$ em 55 dias de cultivo. O feijão-caupi apresentou-se como de grande potencial para uso na adubação verde em períodos curtos de cultivo.

PALAVRAS-CHAVE: Vigna unguiculata, fixação biológica de nitrogênio, nodulação.
ABSTRACT: The purpose of this research was to evaluate the performance of cowpea (Vigna unguiculata) as green manure and also the viability of co-inoculation of seeds with Bradyrhizobium sp. (SEMIA 6462) and Bacillus subtilis (PRBS-1). The experiment was carried out in Argisoil from April to June 2008 in Presidente Prudente, State of Sao Paulo. Four treatments were evaluated in randomized blocks design (T1- Cowpea control; T2- cowpea inoculated with Bradyrhizobium sp; T3- Cowpea inoculated with B. subtilis; T4-Cowpea inoculated with Bradyrhizobium sp and co-inoculated with B. subtilis. BRS Guariba cowpea cultivar was utilized. Nodulation, biomass and total $N$ accumulation were evaluated at two time periods (40 and 55 days after sowing). The inoculation with the strain of Bradyrhizobium commercially recommended increased nodulation in plants. A simple inoculation of cowpea with B. subtilis provided the greatest plant growth and $N$ fixation and did not affect nodulation. However, the co-inoculation did not affect the parameters assessed. In the treatment where B. subtilis was inoculated in cowpea, $5.0 \mathrm{Mg}$ of dry matter per hectare was produced with accumulation of $209 \mathrm{~kg} / \mathrm{N}$ at 55 days of sowing. Cowpea presented good potential for use in green manure for short cultivation periods.

KEYWORDS: Vigna unguiculata, nitrogen fixation, nodulation. 


\section{Introdução}

O feijão-caupi (Vigna unguiculata (L.) Walp.), também conhecido como feijão-de-corda ou feijão-macassar, tem grande importância socioeconômica no Brasil, onde se constitui em componente da dieta alimentar (FREIRE FILHO; LIMA; RIBEIRO, 2005). A leguminosa apresenta alta tolerância aos estresses hídricos, térmicos e salinos, sendo capaz de se beneficiar grandemente da fixação biológica de nitrogênio (FBN) (MARTINS; NEVES; RUMJANEK, 1997). Além disso, o feijão-caupi tem o potencial de uso como adubo verde para incorporação de nitrogênio em cultivos orgânicos (CASTRO et al., 2004). O uso de leguminosas como plantas de cobertura ou adubação verde revela-se como estratégia promissora para aumento de sustentabilidade em agroecossistemas. Os benefícios relacionados a esta prática podem ser relacionados ao aporte de massa seca às áreas cultivadas, FBN, proteção do solo contra erosões e controle de plantas espontâneas (GUERRA et al., 2007). Uma das limitações ao uso da adubação verde na rotação de culturas está relacionada ao período e tempo do cultivo, para que não causem prejuízo à cultura comercial. Nesse sentido, o feijãocaupi tem grande vantagem por ser uma espécie de ciclo curto (FREIRE FILHO; LIMA; RIBEIRO, 2005).

A inoculação de estirpes de Bradyrhizobium spp., em sementes de feijão-caupi, recomendadas comercialmente, não consegue produzir benefícios significativos no rendimento da planta devido à competição com as estirpes nativas do solo (GUALTER et al., 2008). Por isso, é importante o desenvolvimento de novas estratégias que visam melhorar o desempenho da leguminosa durante a simbiose com o rizóbio. Uma estratégia promissora tem sido baseada na coinoculação de sementes com bactérias promotoras de crescimento, como forma de melhorar o desempenho da leguminosa hospedeira (ARAÚJO; HUNGRIA, 1999). Utilizando essa estratégia, foi demonstrado que a associação do Bradyrhizobium spp. com rizobactérias proporcionou ganhos de nutrição em feijão-caupi (SILVA; SILVA; FIGUEIREDO, 2006).

A rizobactéria Bacillus subtilis promove controle biológico de doenças no solo, indução de resistência a doenças da parte aérea, promoção de crescimento de plantas, além de incrementar a nodulação em leguminosas quando coinoculada com o rizóbio (ARAÚJO, 2008a). A utilização dessa espécie bacteriana em cultivos agrícolas pode trazer ganhos adicionais ao desenvolvimento das plantas, os quais precisam ser avaliados para sustentar futuras adoções de novas práticas agrícolas.

Nesse sentido, este trabalho tem por objetivo avaliar a produção de massa seca e a fixação de $\mathrm{N}$ em feijão-caupi em função da coinoculação de sementes com Bradyrhizobium e Bacillus subtilis.

\section{Material e Métodos}

$\mathrm{O}$ experimento foi conduzido no município de Presidente Prudente, SP, durante os meses de abril a junho de 2009, utilizando-se a cultivar de feijão-caupi BRS, Guariba. Esta cultivar tem ciclo de aproximadamente 65 a 70 dias (FREIRE FILHO; LIMA; RIBEIRO, 2005), sendo importante para utilização como adubo verde. O preparo do solo foi realizado por meio uma aração e duas gradagens niveladoras. O solo utilizado foi classificado como Argissolo Vermelho Amarelo Distroférrico (EMBRAPA, 1999), sendo que a amostra foi submetida à análise química (VAN RAIJ et al., 2001) antes da instalação do experimento, apresentando os seguintes atributos: $\mathrm{pH}\left(\mathrm{CaCl}_{2}\right)$ - 6,6; matéria orgânica - 41,0 $\mathrm{g} \mathrm{kg}^{-1}$; $\mathrm{P}-135 \mathrm{mg} \mathrm{dm}^{-3} ; \mathrm{K}-6,6 \mathrm{mmol} \mathrm{dm}^{-3} ; \mathrm{Ca}-88 \mathrm{mmol}_{\mathrm{c}} \mathrm{dm}^{-3}$; $\mathrm{Mg}$ - $21 \mathrm{mmol}_{\mathrm{c}} \mathrm{dm}^{-3}$; CTC $=135,0 \mathrm{mmol}_{\mathrm{c}} \mathrm{dm}^{-3}$; e saturação de bases de $94 \%$. O modelo de delineamento experimental utilizado foi de blocos ao acaso com 4 tratamentos e 5 repetições. Cada parcela foi formada por 6 fileiras de $4 \mathrm{~m}$ de comprimento, espaçadas por $45 \mathrm{~cm}$. A densidade de semeadura utilizada foi de 15 sementes por metro linear. O experimento foi dividido em 4 tratamentos distribuídos em 20 parcelas com $4 \mathrm{~m}$ de comprimento com 6 linhas espaçadas de $45 \mathrm{~cm}$, sendo utilizadas 15 sementes por metro linear. Foram conduzidos os seguintes tratamentos: Tratamento 1- Feijão-caupi sem inoculação; Tratamento 2- Feijão-caupi inoculado com Bradyrhizobium sp. (Semia 6462); Tratamento 3- Feijão-caupi inoculado com Bacillus subtilis (PRBS-1); e Tratamento 4- Feijão-caupi inoculado com Bradyrhizobium sp. (Semia 6462) e coinoculado com Bacillus subtilis (PRBS-1).

Nos tratamentos com inoculação das sementes com Bradyrhizobium sp.(Semia 6462), utilizou-se inoculante turfoso comercial recomendado para o feijão-caupi fornecido pela TURFAL, Curitiba, PR. O inoculante apresentava a concentração de $1,0.10^{9}$ células $\mathrm{g}^{-1}$. Para a inoculação, as sementes foram inicialmente submetidas ao tratamento com solução adesiva aquosa à base de açúcar cristal (10\% de açúcar), na proporção de $1 \mathrm{~mL}$ da solução para $1,0 \mathrm{~kg}$ de sementes. Depois desse procedimento, foi realizada a inoculação das sementes com Bradyrhizobium sp. na proporção de $100 \mathrm{~g}$ do inoculante para $15 \mathrm{~kg}$ de sementes. Posteriormente, foi realizada a inoculação das sementes com Bacillus subtilis. Para isso, a estirpe PRBS-1 (ARAÚJO; HENNING; HUNGRIA, 2005) foi multiplicada durante 7 dias em $100 \mathrm{~mL}$ de caldo nutriente. Decorrido esse período, o meio de cultura foi centrifugado e o precipitado, contendo as células de $B$. subtilis, foi misturado a $500 \mathrm{~g}$ de torta de soja (textura fina, $<210 \mathrm{~mm}$ ) e secado durante 48 horas em estufa a $60{ }^{\circ} \mathrm{C}$. O produto final apresentava a concentração de $1,010^{9}$ células $\mathrm{g}^{-1}$ de $B$. subtilis. O produto foi então misturado às sementes, utilizando-se a proporção de $500 \mathrm{~g}$ do produto para $50 \mathrm{~kg}$ de semente. A inoculação das sementes e a semeadura foram realizadas no mesmo dia.

Aos 40 e aos 55 dias (início da formação de vagens e enchimento dos grãos) após a semeadura, foram coletadas 10 plantas ao acaso, na área útil de cada parcela, para avaliação de nodulação. As plantas foram coletadas com as raízes retiradas com profundidade de até $40 \mathrm{~cm}$, com o devido cuidado para evitar perda de nódulos; após lavagem das raízes e separação dos nódulos, estes foram contados e secados em estufa com circulação de ar forçada à temperatura de $65^{\circ} \mathrm{C}$ a $70{ }^{\circ} \mathrm{C}$, até massa constante, e, em seguida, pesados. $\mathrm{Na}$ área útil de cada parcela, também foi demarcado previamente $1 \mathrm{~m}^{2}$, onde se fez a coleta das plantas para avaliação da massa 
seca produzida por $\mathrm{m}^{2}$. As plantas foram cortadas rentes ao solo e colocadas para secar em estufa de circulação forçada de ar de $65{ }^{\circ} \mathrm{C}$ a $70{ }^{\circ} \mathrm{C}$, até massa constante, em seguida, pesadas e, posteriormente, moídas para determinação do teor de $\mathrm{N}$ foliar, pelo método N-Kjeldhal (MALAVOLTA; VITTI; OLIVEIRA, 1997). O N acumulado na parte aérea foi calculado, multiplicando-se a massa seca das plantas pelos seus respectivos teores de N. Os valores obtidos de massa seca e N acumulados foram transformados para megagrama por hectare $\left(\mathrm{Mg} \mathrm{ha}^{-1}\right)$. Os dados de temperatura média e precipitação diária, durante o período de condução do experimento foram obtidos na estação meteorológica instalada a aproximadamente $500 \mathrm{~m}$ do experimento.

Para efeito de análise estatística, os dados foram submetidos à análise de variância, utilizando-se o teste de Tukey a 5\% para comparação das médias dos tratamentos.

\section{Resultados e Discussão}

A temperatura média diária oscilou entre $15^{\circ} \mathrm{C}$ e $25^{\circ} \mathrm{C}$, durante a condução do experimento, e o acumulado de chuvas durante o experimento foi de $178 \mathrm{~mm}$, distribuídos em períodos distintos (Figura 1). Os perfis de temperatura e precipitação encontrados, durante o período do experimento, são típicos do outono na região Sudeste.

De acordo com as Figuras 2 e 3, observa-se que apenas aos 55 dias após a semeadura (DAS), ocorreram diferenças significativas pelo teste $\mathrm{F}(\mathrm{P}<0,05)$ na nodulação. As sementes inoculadas apenas com o rizóbio apresentaram melhor desempenho nesse quesito, apesar de que a inoculação apenas com $B$. subtilis proporcionou também aumento da massa seca de nódulos aos 55 DAS, em comparação com a testemunha. A nodulação encontrada na testemunha revela que, no local do experimento, existe comunidade estabelecida de Bradyrhizobium spp., a qual desenvolveu simbiose com o feijão-caupi, apesar de não haver histórico de cultivos recentes da leguminosa no local. Há relatos da associação do feijão-caupi com pelo menos seis espécies conhecidas de rizóbio, além de outras espécies não identificadas (ZILLI et al., 2006). Isso reforça a tese de que o feijão-caupi não apresenta especificidade dentro da relação simbiótica, ou seja, a planta pode desenvolver simbiose e formar nódulos com várias espécies de rizóbio encontradas no solo. Essa ausência de especificidade hospedeira justifica os vários relatos encontrados de insucessos de inoculação de caupi, em diversos locais, nos quais é constatado que a testemunha apresenta desempenho de nodulação semelhante aos tratamentos inoculados (GUALTER et al., 2008; SILVA et al., 2008; NASCIMENTO et al., 2008).

A coinoculação do rizóbio com $B$. subtilis não conseguiu incrementar, significativamente, a nodulação no feijão-caupi (Figura 2), diferentemente do que foi relatado por Araújo et al. (2010), com aumento da nodulação e fixação de $\mathrm{N}$, quando se fez a coinoculação de ambas as espécies microbianas em condições de casa de vegetação.

$\mathrm{Na}$ avaliação de produção de massa seca da parte aérea de feijão-caupi, efetuada aos 40 e 55 dias após a semeadura, foi observado que o tratamento que recebeu a inoculação com B. subtilis promoveu crescimento significativo $(\mathrm{P}>0,05) \mathrm{da}$ planta na avaliação aos 55 dias (Tabela 1). Esse resultado demonstra que a inoculação de sementes, apenas com Bacillus subtilis, promoveu maior crescimento da planta, confirmando os resultados encontrados por Araújo (2008b) em soja, milho e algodão. Em relação à produção de massa seca

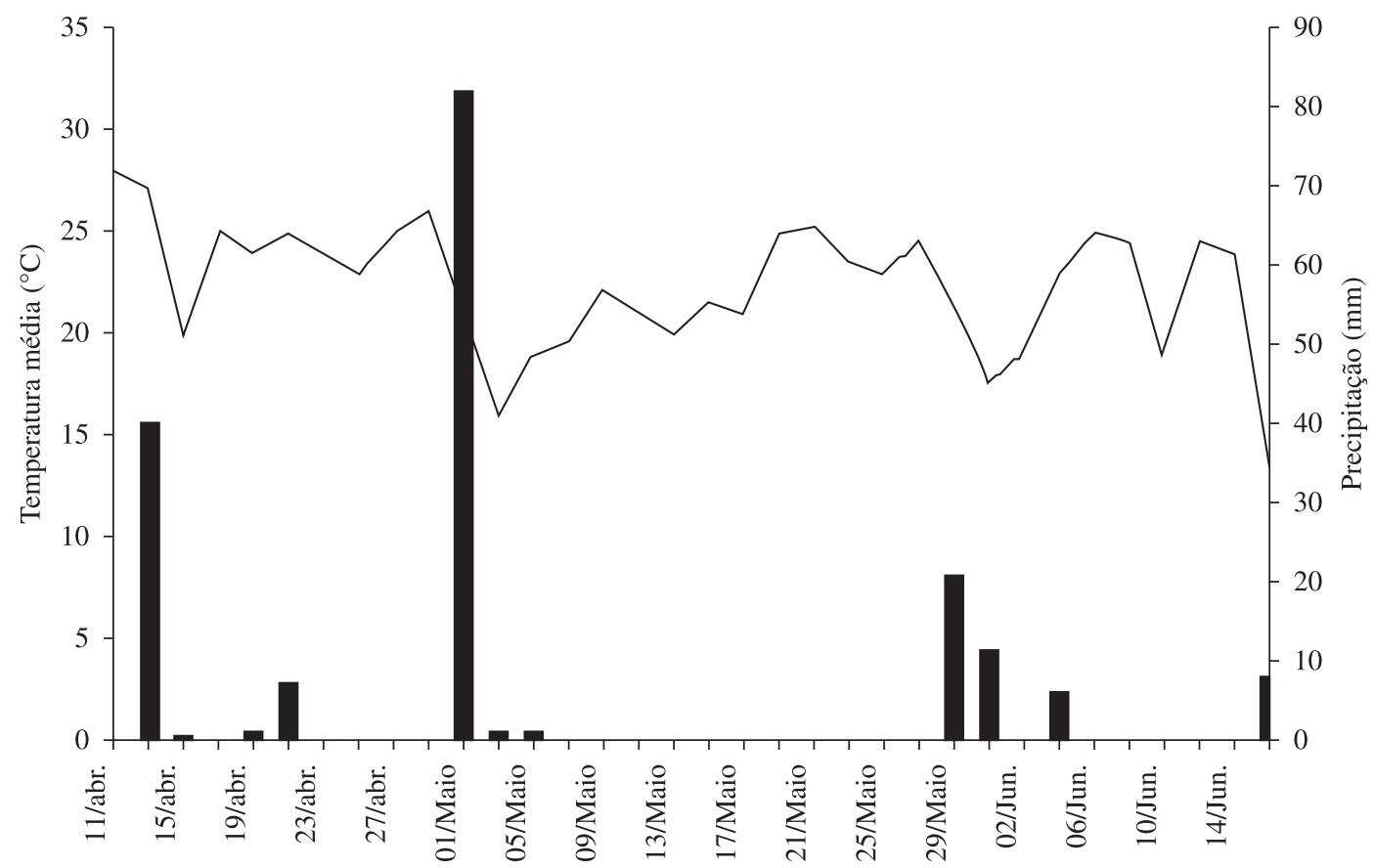

Figura 1. Precipitação pluviométrica (gráfico em colunas) e temperatura média diária (gráfico em linha), durante o período de condução do experimento em campo, Presidente Prudente, SP. 


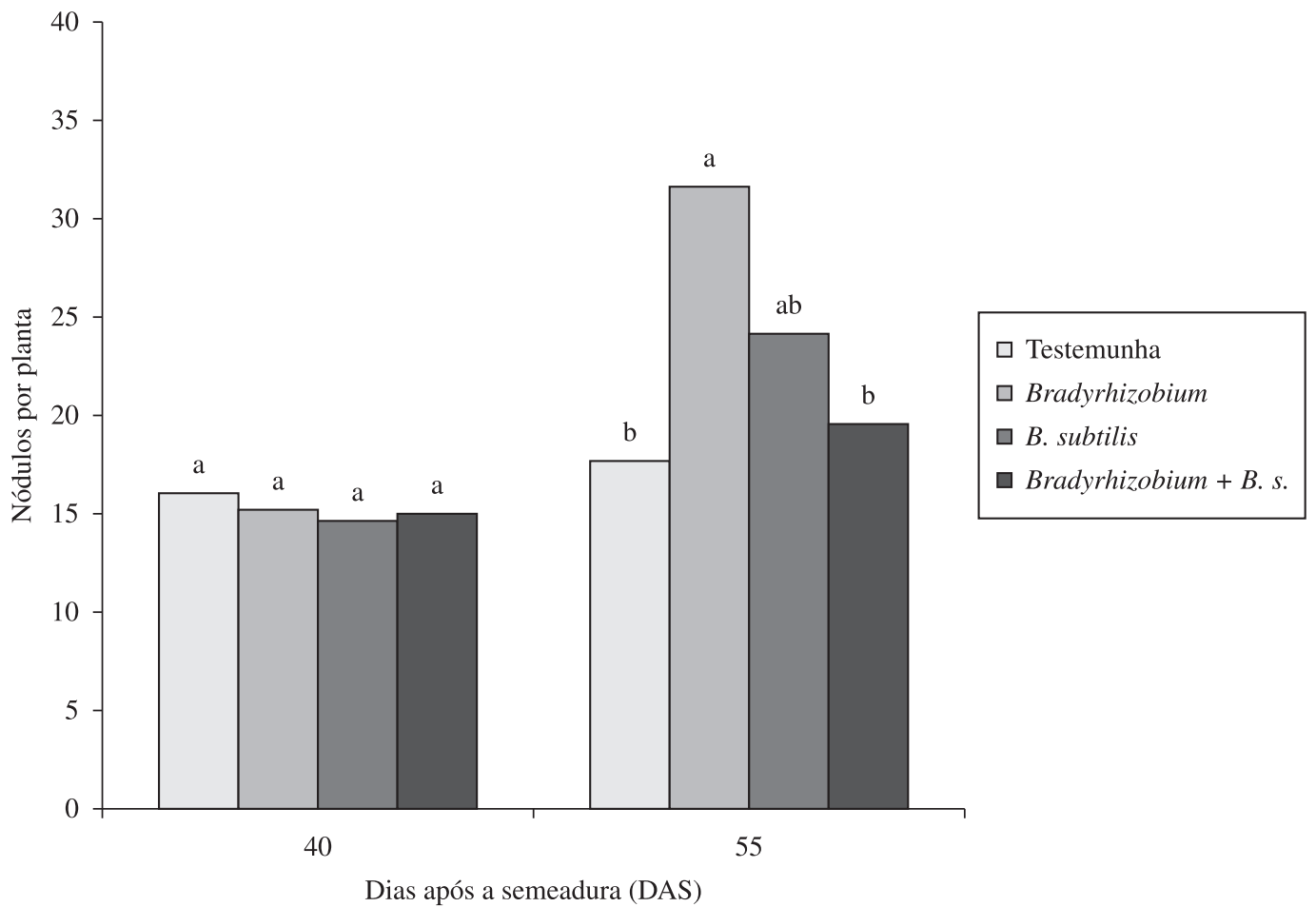

Figura 2. Nodulação em feijão-caupi aos 40 e 55 dias após a semeadura em função da inoculação das sementes com Bradyrhizobium sp. e Bacillus subtilis. Colunas com mesma letra, dentro de cada período de avaliação, não diferem pelo teste de Tukey a $5 \%$ de probabilidade.

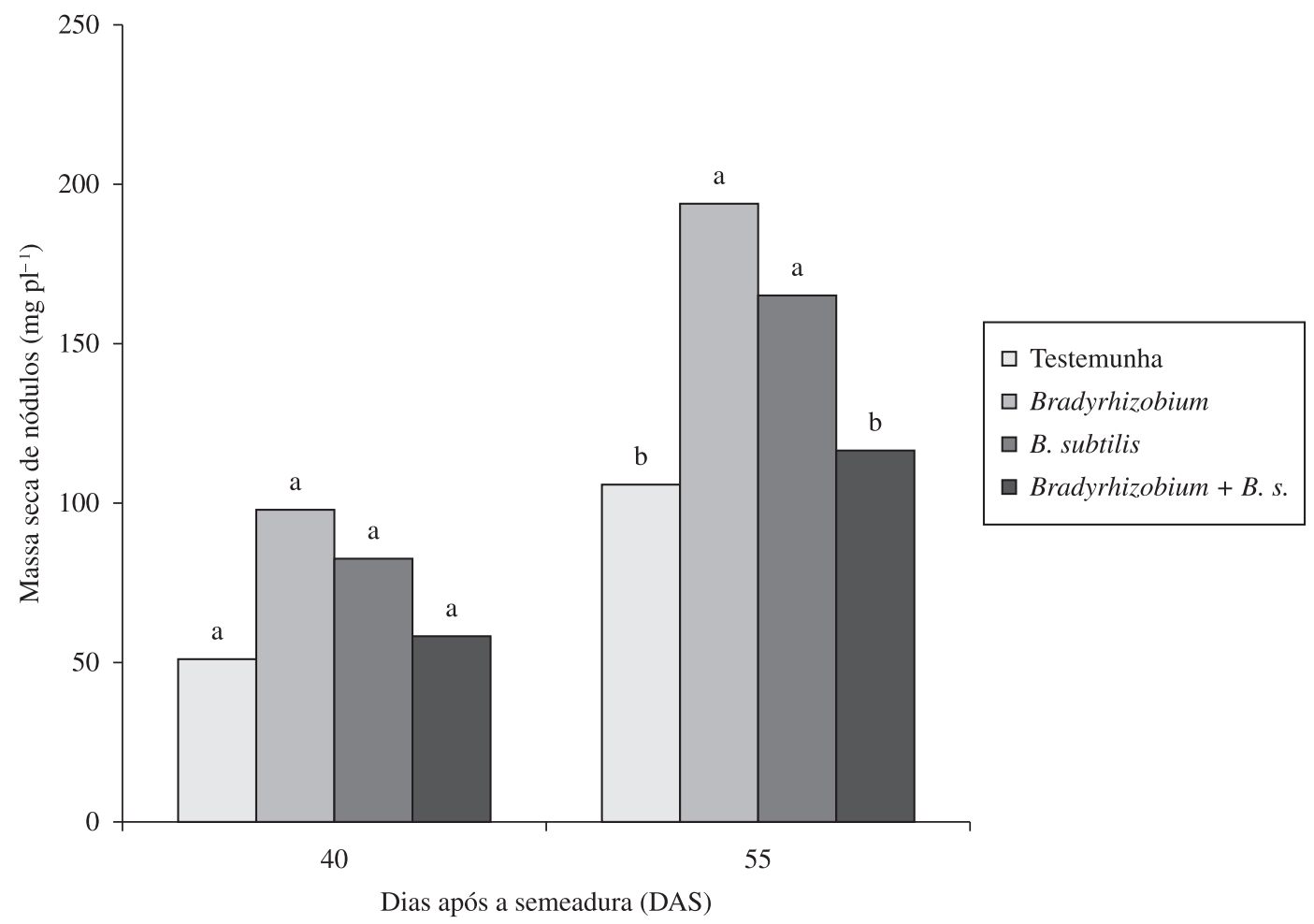

Figura 3. Massa seca de nódulos em feijão-caupi aos 40 e 55 dias após a semeadura, em função da inoculação das sementes com Bradyrhizobium sp. e Bacillus subtilis. Colunas com mesma letra, dentro de cada período de avaliação, não diferem pelo teste de Tukey a 5\% de probabilidade.

por hectare, o valor encontrado na testemunha foi semelhante ao observado por Silva et al. (2005), que conduziu a cultura do feijão-caupi durante 69 dias e encontrou a produção de $3,52 \mathrm{Mg} \mathrm{ha}^{-1}$, com a finalidade de incorporação no solo como adubação verde para o cultivo de milho. Em um trabalho com cultivo de leguminosas de inverno (trevo-branco e cornichão) semeadas em maio, como fonte de $\mathrm{N}$ para a cultura do arroz, foi encontrada produção média de massa seca na parte aérea de $5,3 \mathrm{Mg} \mathrm{ha}^{-1}$ em ciclo médio de 150 dias (SCIVITTARO et al., 2002). O tratamento em que se inoculou apenas $B$. subtilis 
Tabela 1. Produção de massa seca da parte aérea em feijão-caupi aos 40 e 55 dias após a semeadura (DAS), em função da inoculação com Bradyrhizobium sp. e Bacillus subtilis.

\begin{tabular}{lccc}
\hline \multirow{2}{*}{ Tratamentos } & \multicolumn{2}{c}{ Massa seca $\left(\mathbf{M g ~ h a}^{-1}\right)$} & Valor relativo \\
\cline { 2 - 3 } & 40 DAS & $\mathbf{5 5}$ DAS & $(\%)^{\mathbf{2}}$ \\
\hline Testemunha & $1,09 \mathrm{a}^{1}$ & $3,28 \mathrm{~b}$ & 100 \\
Bradyrhizobium & $1,17 \mathrm{a}$ & $4,56 \mathrm{ab}$ & 139 \\
B. subtilis & $1,25 \mathrm{a}$ & $5,00 \mathrm{a}$ & 152 \\
Bradyrhizobium+B. subtilis & $1,27 \mathrm{a}$ & $4,01 \mathrm{ab}$ & 122 \\
C.V.(\%) & 14,8 & 10,3 & \\
\hline
\end{tabular}

${ }^{1}$ Médias seguidas de mesma letra nas colunas não diferem pelo teste de Tukey a $5 \%$ de probabilidade; ${ }^{2}$ Considerando $100 \%$ o valor da testemunha aos 55 DAS.

Tabela 2. Acúmulo de $\mathrm{N}$ em feijão-caupi aos 40 e 55 dias após a semeadura (DAS), em função da inoculação com Bradyrhizobium spp. e Bacillus subtilis.

\begin{tabular}{|c|c|c|c|}
\hline \multirow{2}{*}{ Tratamentos } & \multicolumn{2}{|c|}{$\mathrm{N}$ acumulado $\left(\mathrm{kg} \mathrm{ha}^{-1}\right)$} & \multirow{2}{*}{$\begin{array}{c}\text { Valor relativo } \\
(\%)^{2}\end{array}$} \\
\hline & 40 DAS & 55 DAS & \\
\hline Testemunha & $45,36 a^{1}$ & $133,9 \mathrm{~b}$ & 100 \\
\hline Bradyrhizobium & 48,96 a & $188,8 \mathrm{ab}$ & 141 \\
\hline B. subtilis & $53,28 \mathrm{a}$ & $209,2 \mathrm{a}$ & 156 \\
\hline Bradyrhizobium + B. subtilis & 50,8 a & $159,6 \mathrm{ab}$ & 119 \\
\hline C.V. $(\%)$ & 4,71 & 11,3 & \\
\hline
\end{tabular}

${ }^{1}$ Médias seguidas de mesma letra nas colunas não diferem pelo teste de Tukey a $5 \%$ de probabilidade; ${ }^{2}$ Considerando $100 \%$ o valor da testemunha aos 55 DAS.

na semente de feijão-caupi, produziu $5,0 \mathrm{Mg} \mathrm{ha}^{-1}$ de massa seca em 60 dias de cultivo. Morgado (2006) encontrou rendimento médio de massa seca de $4,5 \mathrm{Mg} \mathrm{ha}^{-1}$ no cultivo de feijão-caupi, durante 72 dias, em 2 anos consecutivos no semiárido nordestino. Com base nesses dados, o desempenho do feijão-caupi inoculado com $B$. subtilis pode ser considerado satisfatório e mostra o potencial de uso dessa técnica para incremento na produção de adubo verde dessa cultura.

Em relação ao acumulo de $\mathrm{N}$ na parte aérea, não houve diferenças significativas entre a testemunha e a estirpe de Bradyrhizobium sp. inoculada sozinha ou associada a $B$. subtilis (Tabela 2). Entretanto, o tratamento, apenas com o B. subtilis, apresentou desempenho significativo no quesito acúmulo de $\mathrm{N}$ na planta, quando comparado à testemunha aos 55 dias, o que foi decorrente também da maior produção de massa seca na parte aérea nesse tratamento. Os resultados encontrados indicam que a coinoculação de B. subtilis e Bradyrhizobium sp. não incrementou a produção de massa seca e o consequente acúmulo de $\mathrm{N}$ na planta, mas $B$. subtilis inoculado sozinho proporcionou aumento na massa de nódulos nas plantas (Figura 3), sugerindo que esse tratamento contribuiu, de alguma forma, para rizóbios nativos fixarem mais $\mathrm{N}$ em simbiose com o feijão-caupi. Salientando também que a inoculação de apenas uma bactéria na semente proporciona maior potencial do inóculo, ou seja, maior quantidade de bactérias é adicionada ao solo via semente.
O maior acúmulo de $\mathrm{N}$ na parte aérea do feijão-caupi, proporcionado pela inoculação apenas com B. subtilis, confirma potencial da rizobactéria para incrementar o crescimento da planta e colaborar, de alguma maneira, para fixação biológica de $\mathrm{N}$ por rizóbios nativos, como também já foi apresentada a produção de amônia por isolados de Bacillus, que pode contribuir para maior acúmulo de $\mathrm{N}$ nas plantas (MARQUES et al., 2010). Além disso, os valores de acúmulo de $\mathrm{N}$ encontrados na maioria dos tratamentos aos 55 dias, após a semeadura, são superiores aos encontrados em trabalhos com outras leguminosas tais como crotalária (136 kg de $\left.\mathrm{N} \mathrm{ha}^{-1}\right)$ e trevo persa $\left(165,8 \mathrm{~kg}^{\mathrm{de}} \mathrm{N}^{-1}\right)$, em épocas de cultivo semelhantes, com ciclos de 80 e 150 dias, respectivamente (ALCANTARA et al., 2000; SCIVITTARO et al., 2002). Ressaltando-se, também, que o tempo reduzido de cultivo do feijão (55 dias) é extremamente importante para utilização desta planta na entressafra da cultura principal.

\section{Conclusões}

- A inoculação do feijão-caupi, apenas com a estirpe de Bradyrhizobium, aumenta a nodulação da planta, enquanto que Bacillus subtilis, inoculado sozinho, contribui para maior produção de massa seca e acúmulo de $\mathrm{N}$ na leguminosa.

- O feijão-caupi apresenta potencial para uso como adubo verde em curto período de cultivo.

\section{Referências}

ALCANTARA, F. A. et al. Adubação verde na recuperação da fertilidade de um latossolo vermelho-escuro degradado. Pesquisa Agropecuária Brasileira, v. 35, p. 227-288, 2000. http://dx.doi. org/10.1590/S0100-204X2000000200006

ARAÚJO, F. F. Bacillus subtilis no controle biológico de doenças e crescimento de plantas. In: ARAÚJO, A. S. F. et al. (Eds.). Matéria orgânica e organismos do solo. Teresina: EDUFPI, 2008a. p.135-148

ARAÚJO, F. F. Inoculação de sementes com Bacillus subtilis, formulado com farinha de ostras e desenvolvimento de milho, soja e algodão. Ciência e Agrotecnologia, v. 32, p. 456-462, 2008 b. http://dx.doi.org/10.1590/S1413-70542008000200017

ARAÚJO, F. F.; HUNGRIA, M. Nodulação e rendimento de soja co-infectada com Bacillus subtilis e Bradyrhizobium japonicum/B. elkanii. Pesquisa Agropecuária Brasileira, v. 34, p. 1633-1643, 1999. http://dx.doi.org/10.1590/S0100204X1999000900014

ARAÚJO, F. F.; HENNING, A.; HUNGRIA, M. Phytohormones and antibiotics produced by Bacillus subtilis and their effects on seed pathogenic fungi and on soybean root development. World Journal Microbiology and Biotechnology, v. 21, p. 1639-1645, 2005. http://dx.doi.org/10.1007/s11274-005-3621-x

ARAÚJO, A. S. F. et al. Co-inoculação rizóbio e Bacillus subtilis em feijão-caupi e leucena: efeito sobre a nodulação, a fixação de $\mathrm{N}_{2} \mathrm{e}$ o crescimento das plantas. Ciência Rural, v. 40, p. 182-185, 2010. 
CASTRO, M. C. et al. Adubação verde como fonte de nitrogênio para a cultura da berinjela em sistema orgânico. Pesquisa Agropecuária Brasileira, v. 39, p. 779-785, 2004. http://dx.doi.org/10.1590/ S0100-204X2004000800008

EMBRAPA. Solos. Sistema brasileiro de classificação de solos. Rio de Janeiro: Embrapa Produção de Informação, 1999. 412 p.

FREIRE FILHO, F. R.; LIMA, J. A. A.; RIBEIRO, V. Q. Feijãocaupi: avanços tecnológicos. Brasília: Embrapa. Informação tecnológica, 2005. 24 p

GUALTER, R. M. R. et al. Inoculação e adubação mineral em feijão caupi: efeitos na nodulação, crescimento e produtividade. Scientia Agraria, v. 9, p. 469-474, 2008.

GUERRA, J. G. M. et al. Desempenho de leguminosas tropicais perenes como plantas de cobertura do solo. Seropédica: Embrapa Agrobiologia, 2007. 39 p. (Embrapa Agrobiologia. Boletim de Pesquisa e Desenvolvimento, n. 20).

MALAVOLTA, E.; VITTI, G. C.; OLIVEIRA, S. A. Avaliação do estado nutricional das plantas. Piracicaba: Associação brasileira para pesquisa de potassa e do fosfato, 1997. $201 \mathrm{p}$.

MARQUES, A. P. G. C. et al. Assessment of the plant growth promotion abilities of six bacterial isolates using Zea mays as indicator plant. Soil Biology and Biochemistry, v. 42, n. 12, p. 229-1235, 2010.

MARTINS, L. M. V.; NEVES, M. C. P.; RUMJANEK, N. G. Growth characteristics and symbiotic efficiency of rhizobia isolated from cowpea nodules of the north-east region of Brazil. Soil Biology and Biochemistry, v. 29, p. 1005-1010, 1997. http://dx.doi.org/10.1016/ S0038-0717(96)00215-5
MORGADO, L. B. Estudo de densidade de plantio de sorgo e feijão caupí consorciados no semiárido brasileiro. Revista Ciência Agronômica, v. 37, p. 357-363, 2006.

NASCIMENTO, C. S. et al. Nodulação e produção do caupi (Vigna unguiculata $\mathrm{L}$. Walp) sob efeito de plantas de cobertura e inoculação. Revista Brasileira de Ciencia do Solo, v. 32, p. 579-587, 2008. http://dx.doi.org/10.1590/S0100-06832008000200013

SCIVITTARO, W. B. et al. Potencial de utilização de leguminosas de inverno como fonte alternativa de nitrogênio para a cultura do arroz irrigado. Pelotas: Embrapa Clima Temperado, 2002. 5 p. (Embrapa Clima Temperado. Comunicado Técnico, n. 81).

SILVA, P. S. L. et al. Green ear yield in corn grown after cowpea incorporation. Revista Brasileira de Milho e Sorgo, v. 4, p. 215-223, 2005.

SILVA, R. P. et al. Efetividade de estirpes selecionadas para feijão caupi em solo da região semiárida do sertão da Paraíba. Revista Brasileira de Ciencias Agrárias, v. 3, p. 105-110, 2008.

SILVA, V. N.; SILVA, L. E. S. F.; FIGUEIREDO, M. V. B. F. Co-inoculação de sementes de caupi com Bradyrhizobium e Paenibacillus e sua eficiência na absorção de cálcio, ferro e fósforo pela planta. Pesquisa Agropecuária Tropical, v. 36, p. 95-99, 2006.

VAN RAIJ, B. et al. Análise química para avaliação da fertilidade de solos tropicais. Campinas: Instituto Agronômico de Campinas-IAC, 2001. 284 p.

ZILLI, J. E. et al. Symbiotic efficiency of cowpea Bradyrhizobium strains in cerrado soils. Pesquisa Agropecuária Brasileira, v. 41, p. 811-818, 2006. http://dx.doi.org/10.1590/S0100204X2006000500013 